\section{Percussion as an aid to suprapubic bladder aspiration}

Sir,

I read with interest the article by O'Callaghan and McDougall showing the value of checking for the presence of urine in the bladder by ultrasound before attempting suprapubic bladder aspiration.' Not having the benefit of ultrasound for this purpose, I have found gentle percussion very helpful. I palpate the symphysis pubis and then start below the umbilicus and percuss gently from above downwards. As Nelson and Peters state ${ }^{2}$ the neonate's bladder extends above the symphysis pubis as it fills. If I encounter bladder dullness one to two fingerbreadths above the symphysis, then aspiration is worth attempting; otherwise not. The percussion should be gentle because vigorous percussion might stimulate the bladder to void.

Another pitfall to avoid is placing the needle too close to the symphysis pubis and directing it down into the pelvis, which results in the needle going below the bladder. With the baby supine, Nelson and Peters insert the needle $2 \mathrm{~cm}$ above the symphysis and angle it only $10-20^{\circ}$ from the perpendicular. ${ }^{2}$ I find that if a nurse holds the legs and trunk firmly down on the couch (or bed) then that tilts the pelvis forward slightly and I hold the needle perpendicular.

\section{References}

1 O'Callaghan C, McDougall PN. Successful suprapubic aspiration of urine. Arch Dis Child 1987;62:1072-3.

${ }^{2}$ Nelson JD, Peters PC. Suprapubic aspiration of urine in premature and term infants. Pediatrics 1965;36:132-3.

F N PORTER Grantham and Kesteven General Hospital, Grantham,

Lincolnshire NG31 8DG

\section{Ranitidine in the newborn}

Sir,

The report of Rosenthal and Miller describing the use of ranitidine in the newborn' prompts us to draw attention to a complication of the use of cimetidine, the most commonly available $\mathrm{H}_{2}$ antagonist in an intravenous form.

A baby boy, delivered in good condition at 36 weeks' gestation and weighing $1650 \mathrm{~g}$ developed bilateral intraventricular haemorrhages, with normal coagulation, within the first 24 hours of life. Apnoeas ensued and penicillin and gentamycin were commenced, and he was mechanically ventilated for 36 hours. Upper gastrointestinal bleeding occurred on the fourth day and cimetidine in a dose of $20 \mathrm{mg} / \mathrm{kg} /$ day was commenced in four divided intravenous doses. Bleeding was noted from puncture sites after the seventh dose. Platelet count had fallen from $117 \times 10^{9} / 1,36$ hours previously, to $22 \times 10^{9} / l$ with normal coagulation studies. Platelet count rose to normal within four days of stopping the medication. The posthaemorrhagic hydrocephalus which developed became stable and no further episodes of thrombocytopenia or bleeding occurred.
Thrombocytopenia has been reported in a number of adults, and the increased use of $\mathrm{H}_{2}$ antagonists in neonates means that users should be aware of hazardous side effects of drugs previously rarely used in this age group.

\section{Reference}

1 Rosenthal M, Miller PW. Ranitidine in the newborn. Arch Dis Child 1988;63:88-9.

A HABEL and N MURRAY West Middlesex University Hospital, Isleworth, Middlesex TW7 6AF

\section{Neonatal infection and human immunoglobulin}

Sir,

I read with interest the paper by Conway and his colleagues. ${ }^{1}$ It is unfair to say that 'there are few studies on the use of immunoglobulin preparations in premature babies and their conclusions are equivocal' when the authors do not refer to the pioneering work of Professor Sidiropolous, who has clearly shown the beneficial effects of intravenous immunoglobulin (IVIG) in the treatment of neonatal sepsis, ${ }^{2}$ and ourselves, who have shown the effect of IVIG in the prevention of neonatal sepsis. ${ }^{3}$

We are not quite sure how many injections and of what volume were given to each infant. It is not surprising that the concentrations of serum IgG achieved were below that of the term infant. The absorption and bioavailability of the intramuscular preparation and the local blood supply could be responsible. In the study by Sidiropolous and ourselves using IVIG we could achieve serum IgG concentrations greater than those seen in the term infants. ${ }^{23} \mathrm{We}$ also cannot see the justification of giving weekly painful and costly injections to these very tiny infants with very little muscle mass when similar results have been shown previously by us using a single intravenous injection.

It is not entirely possible to exclude nursing bias in favour of not reporting the 'soft signs' of sepsis in infants who were receiving immunoglobulin treatment as the control group did not receive a similar placebo injection.

It would be interesting to known if the author measured serum IgM concentrations as we found them to be increased after IVIG.

\section{References}

1 Conway SP, Gillies DRN, Doherty A. Neonatal infection in premature infants and use of human immunoglobulin. Arch Dis Child 1987;62:1252-6.

2 Sidiropolous D, Bohme U, von Murlat G, et al. Immunoglobulin substitution in the treatment of neonatal sepsis. Schweiz Med Wochenschr 1981;111:1649-55.

${ }^{3}$ Haque KN, Zaidi MH, Haque SK, et al. Intravenous immunoglobulin for prevention of sepsis in preterm and low birth weight infants. Pediatr Infect Dis 1986;5:622-5.

K N HaQue

Department of Paediatrics, College of Medicine and King Khalid University Hospital, Riyadh, Saudi Arabia 